\title{
The Effect of Switching to the High-Efficient Rosuvastatin on the Success of Lipid Lowering Therapy in High Risk Patients. The CORVUS (Controlled Targets for High Vascular Risk Patients Using Effective Statins) Study
}

\author{
Laszlo Mark $^{1 *}$, Istvan Reiber ${ }^{2}$, Laszlo Bajnok ${ }^{3}$, Istvan Karadi ${ }^{4}$ and György Paragh ${ }^{5}$
}

${ }^{1}$ Pandy Kalman Bekes County Hospital, 2nd Department of Medicine - Cardiology, Gyula, Hungary

${ }^{2}$ St. George Fejer County Hospital, 4th Department of Medicine, Szekesfehervar, Hungary

${ }^{3} 1$ st Departments of Medicine, University of Pecs, Pecs, Hungary

${ }^{4} 3$ rd Departments of Medicine, Semmelweis University, Budapest, Hungary

${ }^{5}$ Medical and Health Science Centre, University of Debrecen, 1st Department of Medicine, Debrecen, Hungary

\begin{abstract}
Aim: Achievement of target lipid levels is a one of the most important part of the cardiovascular risk reduction to which an obvious way is to switch from current drug to a stronger statin.

Method: In a 3-month, multicenter, prospective, observational, non-interventional open-label study the change of lipid levels and the rate of target level attainment were investigated in 1385 high cardiovascular risk patients, administering, if possible, rosuvastatin in those with lipid levels over the target values.

Results: During the 3-month treatment period the level of total cholesterol decreased by $25.2 \%$, LDL-cholesterol by $35.0 \%$, triglyceride by $21.0 \%$ and HDL-cholesterol level increased by $5.1 \%$. At the end of the study $96 \%$ of the patients were treated with rosuvastatin in monotherapy or in combination. At the third month the rate of achieving LDL-cholesterol target level was $57.7 \%$ and that of HDL-cholesterol target level was $66.7 \%$ and in case of triglyceride level $48.2 \%$. The majority of patients (1077 persons) belonged to the very high risk category according to the guidelines of 3rd Hungarian Cardiovascular Consensus Conference. Among them the achievement rate of an LDLcholesterol level of $1.8 \mathrm{mmol} / \mathrm{L}$ was proved to be $19.0 \%$.
\end{abstract}

Conclusion: The study confirmed that more frequent use of a high-efficient statin (rosuvastatin) by specialists has a beneficial effect on lipid parameters and also facilitates a higher rate of achieving target lipid levels, but to be more efficient, mainly in the very high risk category cases, the combination therapy has to be used more often.

Keywords: Atherosclerosis; Prevention; Cholesterol; Triglyceride; HDL-cholesterol; Statin

\section{Introduction}

Despite the gradual improvement experienced over the last decades atherosclerotic heart disease remained the leading cause of death in Europe and North-America. Hungarian morbidity and mortality data are unfavorable even if compared to most of neighboring East-Central European countries [1]. At the same time a favorable change occurred also in Hungary regarding the mortality data after 1993, as a result of this life expectancy at birth increased by 4.14 years between 1993 \& 2006 to which improvement of cardiovascular mortality contributed by 1.85 years [2].

In the development of ischemic heart disease beside hypertension, smoking and diabetes mellitus [3,4] abnormal lipid levels play a predominant role. Reduction of high cholesterol level is emphasized by treatment guidelines which also support the importance of achieving the prescribed levels, i.e. target values. Surveys on lipid lowering practice of recent years demonstrate that total and LDL cholesterol levels are achieved more and more frequently [5-8], however, despite the considerable and promising improvement a large gap remains between daily practice and the possibilities [9-11]. According to Hungarian studies the most common reason for failure of target level achievement is that the physicians do not modify the therapy when the patient comes with the laboratory results showing inappropriate lipid levels $[10,12]$.

Out of lipid lowering therapies statins are the first choice drug. Numerous randomized clinical endpoint studies demonstrated their favorable effects on the improvement of morbidity and mortality. There is a significant difference in the lipid lowering effect of each statins, therefore it does matter which statin in what dose is applied. Our objective was to investigate the quality of lipid lowering therapy among controlled conditions in high and very high cardiovascular risk patients and to assess the effect of high efficient statin (rosuvastatin) on target lipid level achievement.

\section{Patients and Methods}

The CORVUS (Controlled Targets for High Vascular Risk Patients Using Effective Statins) study was a 3-month, multicenter, prospective, observational, non-interventional open-label clinical study carried out in 26 sites of Hungary between May and December 2009, and involving 1385 patients.

*Corresponding author: L. Mark, MD, PhD, 2nd Department of Internal Medicine-Cardiology, Pandy Kalman Bekes County Hospital, Semmelweis u. 1, P.O. Box 46, 5701 Gyula, Hungary, Tel: +36-209288053; Fax: +36-66526543; E-mail: mark@pandy.hu

Received November 21, 2011; Accepted January 16, 2012; Published January 18,2012

Citation: Mark L, Reiber I, Bajnok L, Karadi I, Paragh G (2013) The Effect of Switching to the High-Efficient Rosuvastatin on the Success of Lipid Lowering Therapy in High Risk Patients. The CORVUS (Controlled Targets for High Vascular Risk Patients Using Effective Statins) Study. Pharm Anal Acta 4: 267. doi:10.4172/2153-2435.1000267

Copyright: (c) 2013 Mark L, et al. This is an open-access article distributed under the terms of the Creative Commons Attribution License, which permits unrestricted use, distribution, and reproduction in any medium, provided the original author and source are credited. 
Citation: Mark L, Reiber I, Bajnok L, Karadi I, Paragh G (2013) The Effect of Switching to the High-Efficient Rosuvastatin on the Success of Lipid Lowering Therapy in High Risk Patients. The CORVUS (Controlled Targets for High Vascular Risk Patients Using Effective Statins) Study. Pharm Anal Acta 4: 267. doi:10.4172/2153-2435.1000267

Page 2 of 5

The primary outcome measures were percent rate of patients achieving target LDL cholesterol goals and the percent rate of patients achieving $50 \%$ or more reduction in LDL-cholesterol. The secondary outcome measure was percent rate of patients achieving target secondary (total cholesterol, triglyceride, HDL-cholesterol) goals.

Patients at high or very high cardiovascular risk, aged over 18 years, receiving already statin therapy or requiring lipid lowering therapy, with a cholesterol (total cholesterol and/or LDL cholesterol) level above target value were eligible for the data collection program.

1385 patients spent an average of 99.1 days ( $\mathrm{SD} \pm 21.6$ days) in the study. Table 1 summarizes the co-morbidities of the participants, and (Table 2) shows lipid lowering drugs taken at baseline (note: more than one medicine may belong to one patient). Based on co-morbidities the patients belonged to such a high risk category that according to the guidelines of 3rd Hungarian Cardiovascular Consensus Conference (HCCC) the target LDL cholesterol level was at least $2.5 \mathrm{mmol} / \mathrm{L}$. HDL cholesterol target value in male was 1.0 , in female $1.3 \mathrm{mmol} / \mathrm{L}$, and that of triglyceride was $1.7 \mathrm{mmol} / \mathrm{L}$ [13].

1077 out of 1385 participants (78\%) was found to be at very high risk according to HCCC guidelines, 538 male and 539 female patients. Their mean age was $62.8 \pm 10.0$ years, 1071 of them came back for visit 2 and 1060 for visit 3 .

The survey was approved by the Hungarian Medical Research Council and participants gave informed consent. The study was conducted in accordance with the Declaration of Helsinki and GCPICH (International Conference on Harmonization Good Clinical Practice).

\section{Statistics}

Data collection and statistical analyses was performed by WEB2 Research Ltd, Hungary. Statistical analyses were performed with SPSS 7.5. Descriptive statistics are presented as frequencies and percentages for categorical variables and as the mean values \pm SD for continuous variables. Categorical variables were compared using the chi $^{2}$ test. Paired Student's t-test was used for continuous parametric variables. In statistical analyses the confidence intervals (CI) were calculated at a significance level of $95 \%$.

\section{Results}

Totally 1385 patients, 718 males (51.8\%) and 667 females (48.2\%) took part in the study, mean age was 63.0 ( $\mathrm{SD} \pm 10.1$ years), minimum and maximum value was 28 and 89 years. Body weight at the first visit was $82.8 \pm 14.6 \mathrm{~kg}$; body mass index was $29.0 \pm 4.4 \mathrm{~kg} / \mathrm{m}^{2}$ which changed non significantly at visit 3 to $81.8 \pm 13.8 \mathrm{~kg}$ and $28.63 \pm 4.25 \mathrm{~kg} / \mathrm{m}^{2}$.

Out of patients participating at visit 1, 1379 came back for visit 2 and 1358 for visit 3 . Table 3 summarizes the lipid lowering drugs recommended at the different visits. Administration of rosuvastatin predominates and the recommended dose increased continuously as well; at visit 1 the average was $15.4 \mathrm{mg}$, at visit $2,16.6 \mathrm{mg}$ and at visit 3, $17.4 \mathrm{mg}$. The proportion of maximal dose of $40 \mathrm{mg}$ was not high; however, it increased continuously at each visit $(4.8 \%, 6.8 \%$ and $9.1 \%$ respectively).

Lipid levels measured at each visit is demonstrated by (Table 4). Between visit 1 and 3 level of total cholesterol decreased by $25.2 \%$, LDL-cholesterol by $35.0 \%$, triglyceride by $21.0 \%$, at the same time the level of HDL cholesterol showed an increase of $5.1 \%$.

\begin{tabular}{|c|c|c|}
\hline & Patient number & $\%$ \\
\hline Hypertension & 1314 & 94.9 \\
\hline Diabetes mellitus & 589 & 42.5 \\
\hline prior MI & 485 & 35.0 \\
\hline CHD & 954 & 68.9 \\
\hline
\end{tabular}

Table 1: Co-morbidities of study participants.

\begin{tabular}{|c|c|c|}
\hline & $\begin{array}{c}\text { Patient number } \\
(\mathrm{n}=1385)\end{array}$ & $\%$ \\
\hline Atorvastatin & 616 & 44.5 \\
\hline Simvastatin & 421 & 30.4 \\
\hline Fluvastatin & 123 & 8.9 \\
\hline Inegy & 24 & 1.7 \\
\hline Ezetimibe & 20 & 1.4 \\
\hline Fenofibrate & 14 & 0.1 \\
\hline
\end{tabular}

Table 2: Lipid lowering drugs taken by the patients at the time of entering the study (more than one drug may belong to one patient).

\begin{tabular}{|c|c|c|c|c|c|c|}
\hline & \multicolumn{2}{|c|}{ Visit 1 } & \multicolumn{2}{c|}{ Visit 2 } & \multicolumn{2}{c|}{ Visit 3 } \\
\hline & $\begin{array}{c}\text { Patient number } \\
(n=1385)\end{array}$ & $\%$ & $\begin{array}{c}\text { Patient } \\
\text { number } \\
(n=1379)\end{array}$ & $\%$ & $\begin{array}{c}\text { Patient } \\
\text { number } \\
(n=1358)\end{array}$ & $\%$ \\
\hline Rosuvastatin & 1308 & 94.4 & 1326 & 96.2 & 1311 & 96.5 \\
\hline Ezetimibe & 64 & 4.7 & 72 & 5.2 & 99 & 7.3 \\
\hline Atorvastatin & 30 & 2.2 & 19 & 1.4 & 18 & 1.3 \\
\hline Simvastatin & 21 & 1.5 & 15 & 1.1 & 16 & 1.2 \\
\hline Fenofibrate & 28 & 2.0 & 25 & 1.8 & 30 & 2.2 \\
\hline
\end{tabular}

Table 3: Proportion of recommended lipid lowering drugs at the visits (drugs with an occurrence of at least $1 \%$; more than one drug may belong to one patient).

\begin{tabular}{|l|l|c|c|l|}
\hline & & Visit 1 & Visit 2 & Visit 3 \\
\hline Total cholesterol & $(\mathrm{mmol} / \mathrm{L} \pm \mathrm{SD})$ & $6.09 \pm 1.31$ & $4.83 \pm 1.02$ & $4.51 \pm 0.88$ \\
\hline LDL-cholesterol & $(\mathrm{mmol} / \mathrm{L} \pm \mathrm{SD})$ & $3.73 \pm 1.14$ & $2.73 \pm 0.89$ & $2.44 \pm 0.75$ \\
\hline HDL-cholesterol & $(\mathrm{mmol} / \mathrm{L} \pm \mathrm{SD})$ & $1.28 \pm 0.36$ & $1.31 \pm 0.35$ & $1.33 \pm 0.32$ \\
\hline Triglyceride & $(\mathrm{mmol} / \mathrm{L} \pm \mathrm{SD})$ & $2.49 \pm 2.03$ & $1.96 \pm 1.17$ & $1.85 \pm 1.23$ \\
\hline
\end{tabular}

Table 4: Lipid levels at each visit in the entire population.

Primary endpoint of the study was the rate of achieving target LDL value (in this study population at least $2.5 \mathrm{mmol} / \mathrm{L}$ based on the $3^{\text {rd }}$ HCCC guidelines). This rate of $12.7 \%$ found at visit 1 increased to $42.9 \%$ by the time of visit 2 and $57.7 \%$ by visit 3 (Figure 1).

The achievement rate of HDL target levels $(1.0 \mathrm{mmol} / \mathrm{L}$ in male and $1.3 \mathrm{mmol} / \mathrm{L}$ in female patients) was $59.8 \%$ at visit 1 and $66.7 \%$ at visit 3. Triglyceride target value of $1.7 \mathrm{mmol} / \mathrm{L}$ was achieved by $30.1 \%$ of patients at baseline, and $48.2 \%$ at the end of study (Figure 2).

Striving for total lipid control we examined how many patients managed to reach the LDL-cholesterol level of $2.5 \mathrm{mmol} / \mathrm{L}$ and HDL cholesterol and triglyceride target levels altogether at visit 1 and visit 3 . These ratios are presented by (Figure 3).

Out of 1385 participating patients 1077 belonged to the very high risk category according to the $3^{\text {rd }}$ HCCC guidelines. Mean lipid values of this patient group are showed by Table 5 . Achievement rate of LDLcholesterol target value of $1.8 \mathrm{mmol} / \mathrm{L}$ was in this population $2.7 \%$, $13.9 \%$ and $19.0 \%$ at visit 1,2 and 3 , respectively. The target value of HDL cholesterol level was reached by $51.8 \%, 59.0 \%$ and $62.1 \%$, that of triglyceride level by $22.5 \%, 34.1 \%$ and $40.2 \%$ at visit $1-3$, respectively. 
Citation: Mark L, Reiber I, Bajnok L, Karadi I, Paragh G (2013) The Effect of Switching to the High-Efficient Rosuvastatin on the Success of Lipid Lowering Therapy in High Risk Patients. The CORVUS (Controlled Targets for High Vascular Risk Patients Using Effective Statins) Study. Pharm Anal Acta 4: 267. doi:10.4172/2153-2435.1000267

Imaging procedures of atherosclerotic process proved that regression can be expected only if the patient's LDL level decreases at least below $50 \%$ of baseline value [14,15]. In this study the lipid values measured before introducing the lipid lowering drug were not known as patients were already receiving therapy at the time of entering the study (just as it is the case in most patients in the everyday practice). Nevertheless, we had the opportunity to check how many patients managed to reach the $50 \%$ decrease at follow-up visits compared to the LDL-cholesterol level measured at baseline. The rate of these patients was $14.5 \%$ at visit 2 and $21.1 \%$ at visit 3 .

The number of all treatment related adverse events was found to be 35 , among them pain in the muscles and in the joints predominated in 19 cases (emphasizing that in 7 persons it was only a slight complaint), abdominal complaint was experienced in 7 patients, swollen legs in 1 patient, increase of creatine kinase in 5 and increase of liver enzymes in 3 patients. Lipid lowering therapy had to be stopped in 5 cases; 2 patients had pain in the muscles, 1 had pain in the joints, 1 patient developed abdominal complaints and in 1 patient significant increase of liver enzymes was experienced. Relying upon these findings the occurrence of side effects leading to therapy discontinuation was found to be below 4 per thousand.

\section{Discussion}

A part of target value achievement studies is comparative clinical study in which the results of administration of drugs applied according to a predefined protocol are assessed. Another part of studies strives to determine the directions of medical practice. Surveys which suggest a better practical use of treatment principles to the colleagues belong

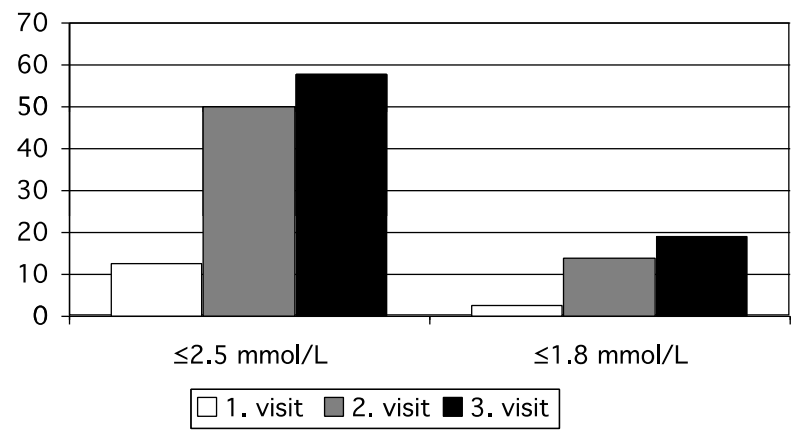

Figure 1: The achievement of 2.5 and $1.8 \mathrm{mmol} / \mathrm{LDL}$-cholesterol goals in the CORVUS study.

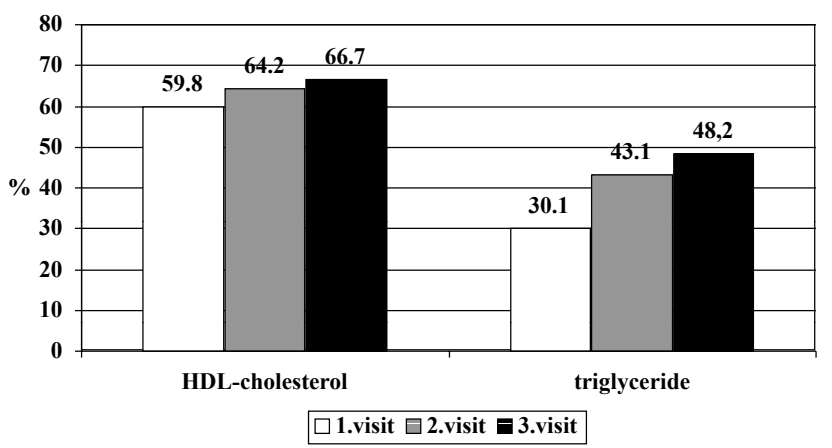

Figure 2: The achievemnet rate of HDL-cholesterol a triglyceride goals at the 1., 2. and 3. visit.
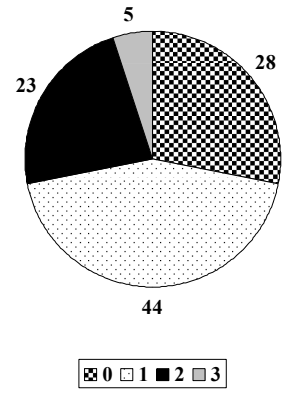

1. visit
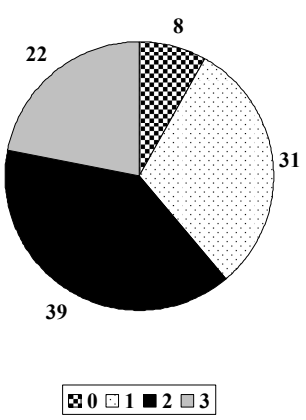

3. visit
Figure 3: The evaluation of total lipid control. The goal achievemnet rate of the 3 lipid parameters at visit 1 and visit 3. (LDL-cholesterol $\leq 2.5$; HDL-cholesterol men: $\geq 1.0$, women: $\geq 1.3$; triglyceride $\leq 1.7 \mathrm{mmol} / \mathrm{L}$ ).

to these. According to the results of these studies the most common reason for failure of target level achievement is that the physicians do not modify the therapy when the patient comes with the laboratory results showing inappropriate lipid levels $[10,12]$. Results of Fox et al. $[16,17]$ demonstrate that in case of introducing a more efficient statin as lipid lowering therapy, dose titration is less frequently necessary. Considering that therapy modification is often missed in the everyday practice, applying a more powerful statin in the first line is even more to be recommended.

The CORVUS study had the aim to assess the practice of specialists by such a way that during a 3-month period with 2 follow-up visits it recommends a switch to rosuvastatin. The results are clearly hopeful, the rate of achieving LDL cholesterol target level of $2.5 \mathrm{mmol} / \mathrm{L}$ increased from $12.7 \%$ at baseline to $57.7 \%$ by the end of the study. This latter one is considered to be quite promising based on Hungarian results published to date (Figure 4) $[12,18]$. On the other hand, the low value at baseline is not satisfying; nevertheless, the results proved that our colleagues can be encouraged for a better quality of work by periodic assessments. Even after this study $42 \%$ of patients remained over the recommended target level. Not to mention that $78 \%$ of the entire study population belonged to the very high risk category and the rate of achieving their LDL cholesterol target level of $1.8 \mathrm{mmol} / \mathrm{L}$ was only $19 \%$ even at the end of study. It is an advantage of our study that unlike in most studies on drugs' effectiveness the rate of achieving $1.8 \mathrm{mmol} / \mathrm{L}$ was established not for the entire study population but only for the very high risk group. This relatively low goal achieving rate in the very high risk group underlines the fact, that beside the continuous lipid profile control a higher administration of the combination therapy (i.e. use of ezetimibe) has to be considered [19].

It is to be emphasized that by administration of rosuvastatin which influences favorably all lipid parameters the achievement rate of HDL cholesterol target value and to a lesser extent that of triglyceride (Table 5) and the rate of patients reaching all three lipid parameter target values increased (Figure 3); although all these were not study objectives.

Guidelines recommend in case of vascular disease also more than $50 \%$ reduction in LDL cholesterol level in addition to achieving the target values $[14,15]$. This was realized in our study in $21.1 \%$ by visit 3 compared to baseline values measured at visit 1 . Based on our data we can only state that regression can be expected at least in so many patients but considering that baseline values measured prior 
Citation: Mark L, Reiber I, Bajnok L, Karadi I, Paragh G (2013) The Effect of Switching to the High-Efficient Rosuvastatin on the Success of Lipid Lowering Therapy in High Risk Patients. The CORVUS (Controlled Targets for High Vascular Risk Patients Using Effective Statins) Study. Pharm Anal Acta 4: 267. doi:10.4172/2153-2435.1000267

the introduction of therapy well before entering the study were even higher, the regression of atherosclerosis can be expected in significantly more patients.

Comparison of medicines listed in (Table 2 and 3) clearly shows that the physicians strived for a higher rate of target value achievement, as more and more patients received stronger statin and rate of ezetimibe use increased continuously, too. Based on these result we can state that the administration of high efficient statins is the way of achieving target value. Moreover it is also evident that following this approach, combination therapy, use of ezetimibe can be a great help when striving for higher quality of work [20,21]. It would be more expedient to include in the guidelines that in case of very high LDL cholesterol level the treatment should not be initiated with the lowest dose, as it is to be feared that dose titration may be missed. Advantages of forced titration are proved by studies as well [22].

The occurrence of side effects was very low also in this study. Developing these side effects may not inevitably result in discontinuation of lipid lowering therapy even in the particular patient (dose reduction, a change to another statin or a combination therapy with low dose statin should be considered instead) and must not divert the physician from purposeful, more efficient treatment of the other patients.

The purpose of the CORVUS study was to demonstrate a higher target lipid goal achievement rate among patients at high cardiovascular risk using more potent lipid-lowering treatment options including high-efficient therapies. It proved that a better reduction of lipids can be achieved by the application of rosuvastatin. The target level achievement rate corresponds to the average of CEPHEUS study performed in several European countries (Figure 5) [7]. After further consideration of our results we can conclude that in addition to keeping the importance of prevention on agenda application of registries,

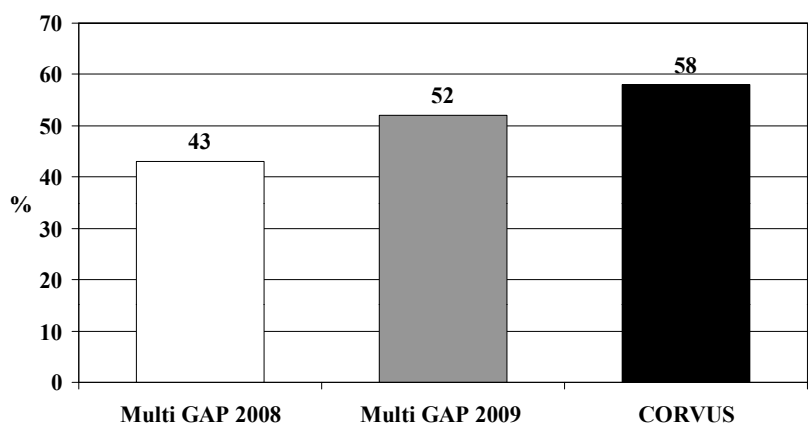

Figure 4: The rate of achievement of $2.5 \mathrm{mmol} / \mathrm{LDL}$-cholesterol goal among the specialists in the Hungarian MULTI GAP 2008 and 2009 studies and the CORVUS study.

\begin{tabular}{|l|l|c|c|c|}
\hline & & $\begin{array}{c}\text { Visit 1 } \\
(n=1077)\end{array}$ & $\begin{array}{c}\text { Visit 2 } \\
(n=1071)\end{array}$ & $\begin{array}{c}\text { Visit 3 } \\
(n=1060)\end{array}$ \\
\hline Total cholesterol & $(\mathrm{mmol} / \mathrm{L} \pm \mathrm{SD})$ & $6.12 \pm 1.29$ & $4.84 \pm 1.03$ & $4.51 \pm 0.90$ \\
\hline LDL-cholesterol & $(\mathrm{mmol} / \mathrm{L} \pm \mathrm{SD})$ & $3.73 \pm 1.12$ & $2.73 \pm 0.89$ & $2.44 \pm 0.76$ \\
\hline $\mathrm{HDL}-$ cholesterol & $(\mathrm{mmol} / \mathrm{L} \pm \mathrm{SD})$ & $1.23 \pm 0.34$ & $1.28 \pm 0.33$ & $1.19 \pm 0.31$ \\
\hline Triglyceride & $(\mathrm{mmol} / \mathrm{L} \pm \mathrm{SD})$ & $2.69 \pm 2.37$ & $2.07 \pm 1.21$ & $1.94 \pm 1.34$ \\
\hline
\end{tabular}

Table 5: Lipid levels at each visit in the very high risk group.

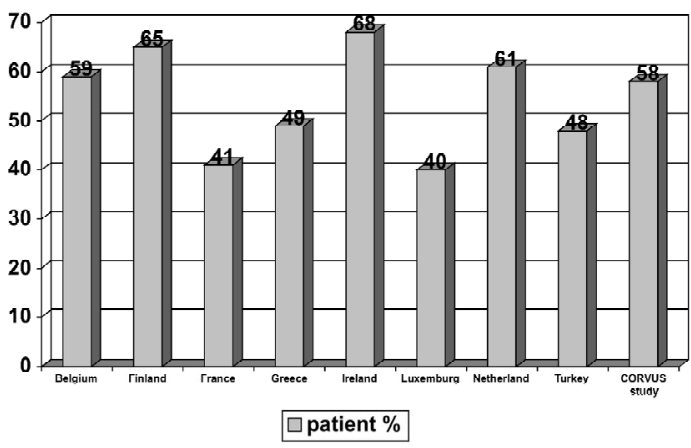

Figure 5: The comparison of LDL-cholesterol goal achievement in the countries of CEPHEUS study and CORVUS study.

educational programs may help the work of colleagues and the optimal lipid lowering treatment of patients.

\section{Declaration of Interest}

This material was written independently, and no company or institution supported the authors financially. No professional writer was involved. All authors had full access to all the data in the study, taken responsibility for the integrity of the data and the accuracy of the data analyses, and agreed to the manuscript as written. The authors have given talks, attended conferences and participated in other trials or advisory boards sponsored by various pharmaceutical companies.

\section{References}

1. The world health report 2002 - Reducing Risks, Promoting Healthy Life.

2. Jozan $P$ (2008) Crisis and renewal in the epidemiological evolution after the second world war in Hungary. First ed. MTA Tarsadalomkutato Központ Budapest.

3. Landini L, Leone A, Mikhailidis DP (2009) Modifying cardiovascular risk factors newer insights and preventive measures. Curr Pharm Des 15: 1034-1037.

4. Desai RV, Banach M, Ahmed MI, Mujib M, Aban I, et al. (2010) Impact of baseline systolic blood pressure on long-term outcomes in patients with advanced chronic systolic heart failure (insights from the BEST trial). Am J Cardiol 106: 221-227.

5. Paragh G, Mark L, Zamolyi K, Pados G, Ofner P (2007) Lipid-modifying therapy and attainment of cholesterol goals in Hungary: the return on expenditure achieved for lipid therapy (REALITY) study. Clin Drug Investig 27: 647-660.

6. Kotseva K, Wood D, De Backer G, De Bacquer D, Pyörälä K, et al. (2009) Cardiovascular prevention guidelines in daily practice: a comparison of EUROASPIRE I, II, and III surveys in eight European countries. Lancet 373: 929-940.

7. Hermans MP, Castro Cabezas M, Strandberg T, Ferrières J, Feely J, et al. (2010) Centralized Pan-European survey on the under-treatment of hypercholesterolaemia (CEPHEUS): overall findings from eight countries. Curr Med Res Opin 26: 445-454.

8. Mark L. Paragh Gy, Karadi I, Reiber I, Pados Gy (2010) Clinical research Changes in attainment of lipid goals by general practitioners and specialists in patients at high cardiovascular risk in Hungary during 2004-2008. Arch Med Sci 6: 695-700.

9. Lenfant C (2003) Clinical research to clinical practice - Lost in translation? N Engl J Med 349: 868-874.

10. Mark L, Dani G, Kiss Z, Katona A (2008) A change of attitude in lipidology, achievement of target levels. What comes next?. Orv Hetil 149: 1731-1736.

11. Katsiki N, Mikhailidis DP, Athyros VG, Hatzitolios Al, Karagiannis A, et al (2010) Are we getting to lipid targets in real life? Arch Med Sci 6: 639-641.

12. Reiber I, Paragh Gy (2009) Achieving the lipid goals in the Hungarian MULT 
Citation: Mark L, Reiber I, Bajnok L, Karadi I, Paragh G (2013) The Effect of Switching to the High-Efficient Rosuvastatin on the Success of Lipid Lowering Therapy in High Risk Patients. The CORVUS (Controlled Targets for High Vascular Risk Patients Using Effective Statins) Study. Pharm Anal Acta 4: 267. doi:10.4172/2153-2435.1000267

Page 5 of 5

GAP (multi goal attainment problem) - the results of a new study on the administration and effectiveness of lipid lowering therapy. Metabolizmus $7: 69$ 72.

13. (2008) The III. Hungarian Cardiovascular Consensus Conference on the risk stratification, prevention and treatment of the diseases of coronary, cerebral and periferial arteries. Metabolizmus 6: 1-99.

14. Nissen SE, Tuzcu EM, Schoenhagen P, Brown BG, Ganz P, et al. (2004) Effect of Intensive Compared with Moderate Lipid-Lowering Therapy on Progression of Coronary Atherosclerosis. A Randomized Controlled Trial JAMA 291: 10711080.

15. Nissen SE, Nicholls SJ, Sipahi I, Libby P, Raichlen JS, et al. (2006) Effect of very high-intensity statin therapy on regression of coronary atherosclerosis. The ASTEROID Trial JAMA 295: 1556-1565

16. Fox KM, Gandhi SK, Ohsfeldt RL, Davidson MH (2007) Comparison of lowdensity lipoprotein cholesterol reduction after switching patients on other statins to rosuvastatin or simvastatin in a real-world clinical practice setting. Am J Manag Care 13: S270-S275.

17. Fox KM, Gandhi SK, Ohsfeldt RL, Blasetto JW, Davidson MH (2007) Titration patterns with rosuvastatin as compared with other statins in clinical practice:
A retrospective observational cohort study using an electronic medical record database. Clinical Therapeutics 29: 2385-2394.

18. Reiber I, Paragh Gy, Mark L (2010) Status report from the abyss - the results from the Hungarian MULTI GAP 2009. Metabolizmus 8: 137-142.

19. Mark L, Paragh Gy, Reiber I (2011) The role of ezetimibe in LDL cholesterol goal attainment in very high risk patients. The rosuvastatin monotherapy looks to be insufficient. Curr Med Res Opin 27: 1959-1960.

20. Ballantyne CM, Weiss R, Moccetti T, Vogt A, Eber B, et al. (2007) Efficacy and safety of rosuvastatin $40 \mathrm{mg}$ alone or in combination with ezetimibe in patients at high risk of cardiovascular disease (results from the EXPLORER study). Am J Cardiol 99: 673-680.

21. Angelopoulos J, Krassakopoulos N, Nathanson R, Boukas S, Sampalis JS (2009) Co-administration of ezetimibe and a statin in management of dyslipidemias: a meta-analysis of clinical trials. Arch Med Sci 5: 347-363.

22. Farsang C, Athyros V, Gaw A (2007) A multicentre, open study to assess the effect of individualizing starting doses of atorvastatin according to baseline LDL-C levels on achieving cholesterol targets: the Achieve Cholesterol Targets Fast with Atorvastatin Stratified Titration (ACTFAST-2) study. Curr Med Res Opin 23: 1945-1956.
This article was originally published in a special issue, Cardiovascular drugs handled by Editor(s). Dr. Camelia Diaconu, Internal Medicine University, Europe 